\title{
Improving Automation and Process Control of an Indirect Gravure (pad) Printing Machine
}

\section{Arash Hakimi Tehrani, Edgar Dörsam}

Technische Universität Darmstadt, Institute of Printing Science and Technology, Magdalenenstr. 2, 64289 Darmstadt, Germany, e-mail: hakimi_a@idd.tu-darmstadt.de,doersam@idd.tu-darmstadt.de

\section{Jann Neumann}

PERFECTA Cutting Systems GmbH, Schäfferstraße 44, D-02625 Bautzen, Germany, e-mail: neumann@perfecta.de

\footnotetext{
Abstract: Because pad printing can be used on 3-D substrates, it has attracted the attention of many researchers in the field of printed electronics. This paper presents developments in the automation of a pad printing machine that improve its specifications for use in scientific fields and equip it with some unique features. Users of this machine can obtain graphs of printing force and printing step durations for tracing and analyzing the printing process. Here, to explain the design method, the printing technique features, the pad printing working process and related machine parts, as well as the development and design process, are described. In this section, some hardware, such as National Instruments CompactRIO, as well as software (LabVIEW) and data transferring under the EtherCAT protocol will also be discussed. Finally, the machine user interface and some analytical graphs of the machine will be explained.
}

Keywords: Automation pyramid; Mechatronic system structure; Indirect gravure printing; Pad printing control system; LabVIEW

\section{Introduction}

Indirect gravure printing is the collective name for an indirect printing process having one transferring part (pad) and one gravure printing form. In many cases, it is referred to as pad printing [5, 10]. Pad printing has some advantages over other printing methods. Because it is a gilt-edged technique for printing on non-smooth objects having concave and convex surfaces, it has a competitive advantage for work with 3-dimensional substrates, which have differing shapes, thicknesses and 
dimensions. This capability makes pad printing suitable for a wide range of uses in a variety of production processes, such as medical instruments, electrical devices, automotive parts and printed electronic devices. This technique has been applied in the medical imaging field to print piezoelectric thick-films on a curved substrate [15]. It has also been used in the production processes of gas sensors [4], solar cells [6, 13], UHF RFIDs [16], OLEDs, biomedical sensors [24], mobile phone antennas [27], and microelectronic circuits [11]. Moreover, it can also be combined with other methods, such as screen printing. For example, in [14], some research success was achieved by combining pad and screen printing to produce an ultrasonic transducer in high frequency scales. Because of the importance of pad printing usage in such scientific fields, this paper focuses on the development of control and automation for pad printing machines, with a focus on their usage in scientific fields. According to scientific research, a more highly automated pad printing machine represents a new demand. Here, automation should provide high accuracy, high value of data transfer and management and high controllability of printing parameters. So, the main contribution of this work is an improvement of the automation level of pad printing machines.

This paper is organized as follows: the next section, introduces basic concepts of mechatronics, automation and pad printing machine. Second, the development concept for the pad printing automation system is presented. Third, the various components of the pad printing machine and its structure are described. Afterward, a flowchart diagram of the machine's working process is offered. Next, we focus on the development of the machine structure, automation level, data flow and software designing process as parts of the development process for the pad printing machine. Then, as examples, some reports of the system are mentioned. Finally, the paper is concluded with a brief summary.

\subsection{Mechatronic System Description}

To achieve this goal, the pad printing machine is developed in the three fields of electronics, control systems, and mechanics. As shown in Figure 1 (a), these fields are all related to a mechatronic system [8]. Therefore, to provide a better description, the pad printing machine is considered as a mechatronic system.

Figure 1 (b) shows the structure of a mechatronic system, which consists of four units: control, sensors, actuators and mechanics [9].

The level of controlling and processing and the user interface is related to the level of system automation, which is described in the next section. 


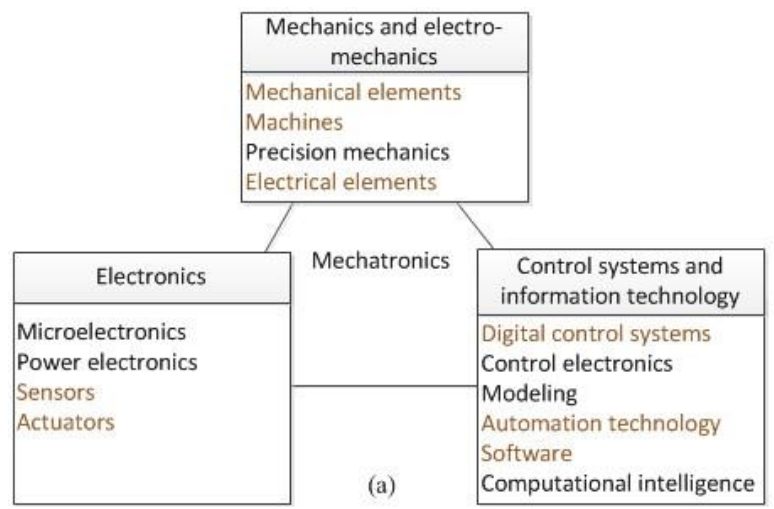

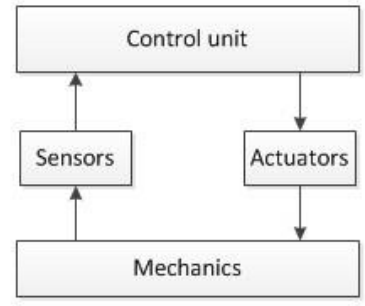

(b)

Figure 1

(a): Mechatronics field concept. The connected lines represent the synergistic integration of these three scientific fields in generating the mechatronics concept. The orange color defines the developed parts that are described in this paper. (b): The mechatronic system structure [9], with its four units of control, sensors, actuators and mechanics. The arrows show the direction of information flow.

\subsection{Automation Description}

Automation is the application of a control system in a process toward the end of reducing human intervention, improving process throughput, and decreasing production losses [1]. The automation pyramid in Figure 2 shows different levels of automation.

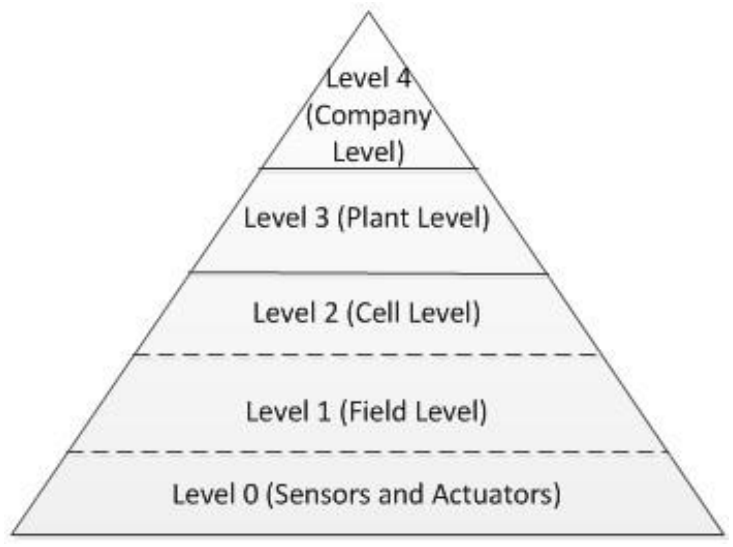

Figure 2

The automation pyramid. The automation development direction is from bottom (low level) to top (high level). In some cases, levels 0,1 and 2 are considered as one group; hence, the dashed lines [9, $23,26]$ 
The possibility of passing through each level to a higher level varies from system to system. In some cases, achieving a particular level is very difficult, or even impossible. Level 0 is achieved merely by use of sensors and actuators to control the (mechatronic) system. Level 1 involves controlling and processing the signals of the system and is called the field level. Level 2 (the cell level) depends on user interface and process monitoring. Level 3 (the plant level) involves optimal scheduling and maintenance, as provided by the manufacturing execution system (MES) and the management information system (MIS). Level 4 (the company level) involves enterprise resource planning (ERP) and the programming and production control of an entire company $[9,23,26]$.

\subsection{Description of Pad Transfer Printing}

Pad printing machines come in two types: pad transfer printing and rotary pad transfer printing. This paper focuses on pad transfer printing. A schematic diagram of pad printing is given in Figure 3. As shown, the pad and printing form are initially located in their reference positions (red dash). The printing form table then advances (step 2). Next, the pad comes down to pick up the ink (step 3), a movement reversed in step 4. In step 5, the printing form table returns to its reference position. Finally, the pad descends to transfer the ink film to the substrate [5] (step 6), and then returns to its reference position in step 7.

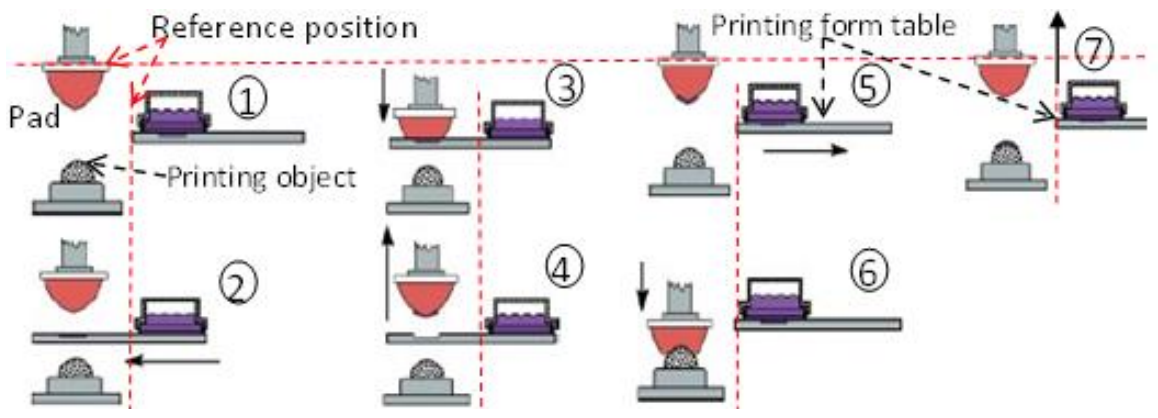

Figure 3

Pad transfer printing schematic diagram showing the pad, printing form table and printing object. The $1^{\text {st }}$ picture shows the start of the process and the $7^{\text {th }}$ picture shows the end, where pad, table and object return to their original position. The arrows define the movement direction [2].

\section{Concept of an Automated Pad Printing Machine}

Over time, there have been some improvements in pad printing machines. Today, most well-known models have features such as variable speed control, printedpieces counter and variable pad position $[17,18,25]$. The pad printing machine 
developed in this project has 4 extra capabilities: printing process force tracing on the substrate and printing forms; position control in both the $\mathrm{X}$ and $\mathrm{Y}$ directions; velocity control in both the $\mathrm{X}$ and $\mathrm{Y}$ directions and user-defined contact time. Within each printing cycle, these parameters can be changed and/or saved for future batches and are traceable in different graph formats for each printed sample. These parameters have been classified in Table 1. As indicated, the force as a printing parameter can be controlled and traced when the pad is pressed on either the printing form or the substrate. The position and velocity of the pad and printing form axes are controlled and traced in two directions: $\mathrm{X}$ and $\mathrm{Y}$. The contact time of the pad on the printing form (for obtaining ink) and on the substrate (for transferring ink) can also be controlled and traced.

Table 1

Categorization of printing parameters according to their controllability and traceability (C\&T) at different axis directions in newly developed pad printing machine

\begin{tabular}{|c|c|c|}
\hline $\begin{array}{l}\text { Printing } \\
\text { parameters }\end{array}$ & $\begin{array}{l}\mathrm{C} \& \mathrm{~T} \text { at } \mathrm{Y}(\mathrm{pad}) \text { axis } \\
\text { direction }\end{array}$ & $\begin{array}{l}\mathrm{C} \& \mathrm{~T} \text { at } \mathrm{X} \text { (printing } \\
\text { form) axis direction }\end{array}$ \\
\hline \multirow{2}{*}{ Force } & Pad on printing form & \multirow{2}{*}{$\mathrm{NO}$} \\
\hline & Pad on substrate & \\
\hline Position & Completely & Completely \\
\hline Velocity & Completely & Completely \\
\hline \multirow{2}{*}{$\begin{array}{l}\text { Contact } \\
\text { time }\end{array}$} & Pad on printing form & \multirow{2}{*}{ Pad on printing form } \\
\hline & Pad on substrate & \\
\hline
\end{tabular}

\section{Categorization of Pad Printing Machine Components according to a Mechatronic System Structure}

The most important movable parts of a pad printing machine are its axes (See Figure 4). These are referred to as the printing form axis and the pad axis. The printing form axis movement is in the forward (X) direction. The movement along the pad axis (Y) is downward, so it has negative values compared to the reference coordinate system.

As shown in Figure 1 (b), a mechatronic system has four parts: control unit, sensors, actuators and mechanics [9]. Thus, the pad printing machine structure can be illustrated as in Figure 5. 


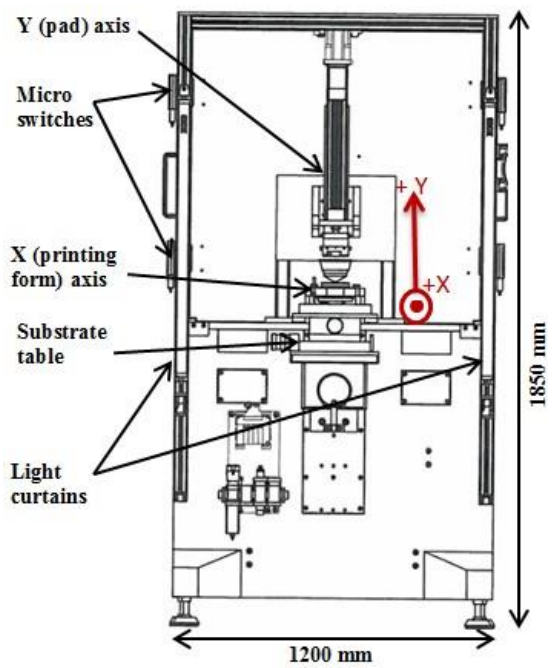

Figure 4

Pad printing machine schema. The dimensions of the machine are 1200 by 980 by $1850 \mathrm{~mm}$. The Y positive direction is upward and $\mathrm{X}$ positive direction is forward [18]. These elements are highlighted to promote a better understanding of the printing machine structure given in Figure 5.

According to the mechatronic structure of Figure 1 (b), the four general units of the new pad printing machine structure and their relationship to each other are described in Figure 5. All processing and logical calculations happen in the control unit. This unit consists of the machine's real-time embedded industrial controller and electric servo drives. As shown, the vertical and horizontal drives receive control data from the real-time controller and send the results back to it. The control unit has another element, identified as software. This element receives the demands of the user in the UI (user interface) and sends them to the Main software block. After processing, these demands are then sent to the real time controller. Further, the controlling program is located at the Main block. The actuators receive the commands of the controlling unit and execute them on the mechanical parts. For example, the vertical drive controls the vertical servomotor (actuator). This actuator moves the vertical axes (mechanical unit), which ultimately moves the pad as a printing unit. The sensors unit is another part of system that measures some parameters of the mechanics unit and then sends them to the control unit for processing. The mechanics unit has the role of mechanically executing user commands. The most important elements of the mechanics unit are shown in Figure 4 and Figure 6 (a). The printing unit is located in the mechanics unit and consists of the pad unit, the inking unit and the object-holding unit [10]. They can be called the operational, input and output units respectively, according to the operating maintenance model for printing [7]. Each of these has special parts, which are shown in Figure 6 (a). 


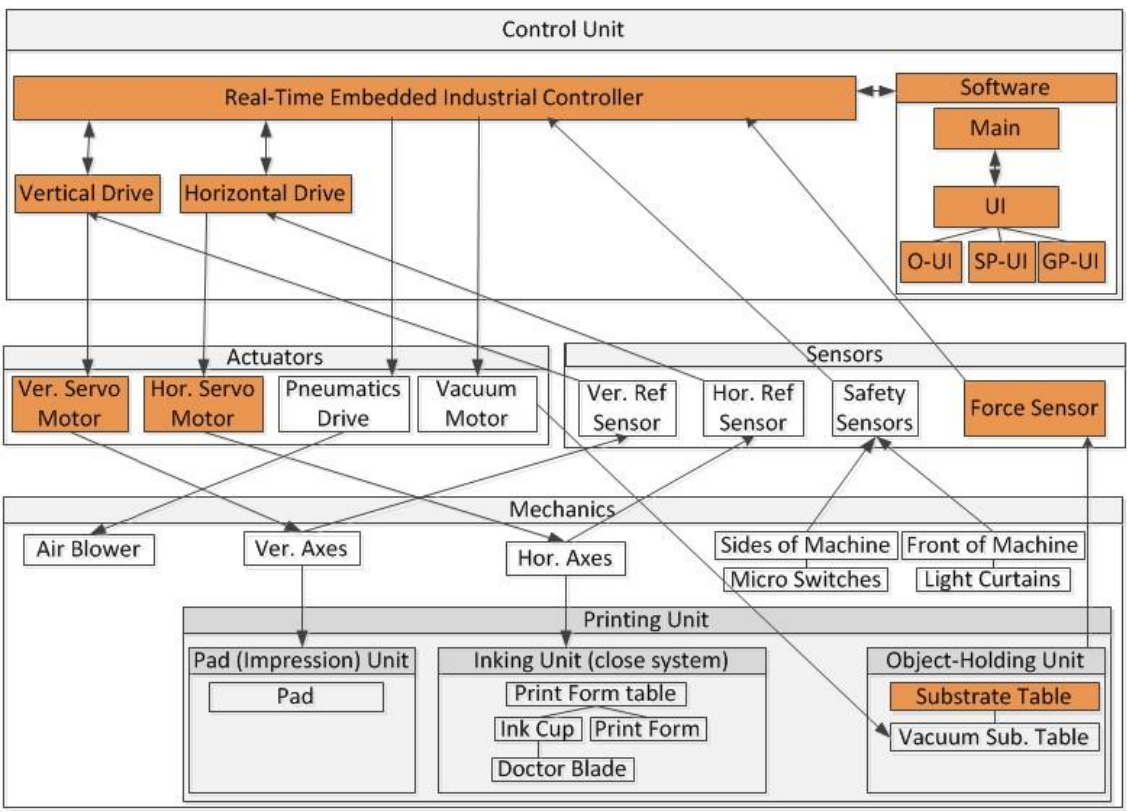

Figure 5

The pad printing machine structure. It is divided into control, actuators, sensors and mechanics units, according to the mechatronic system structure. The arrow directions indicate the machine data flow. The orange color defines the developed parts. The printing unit is considered a part of the mechanics unit and consists of pad, inking and object-holding units. It is classified to help illustrate the development points of the machine.

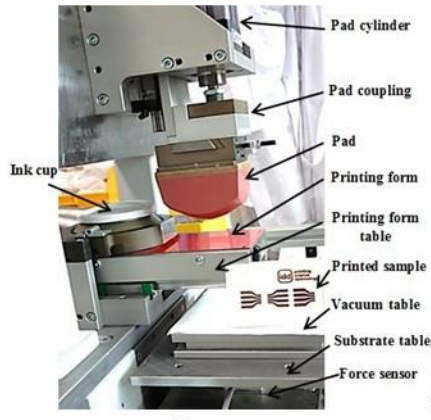

(a)

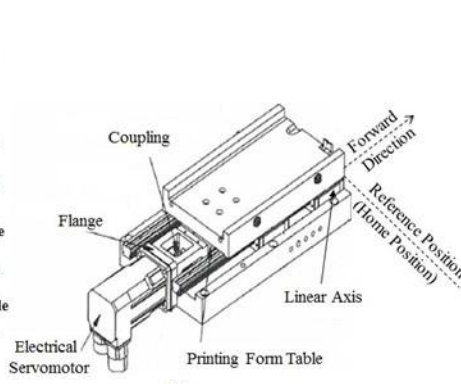

(b)

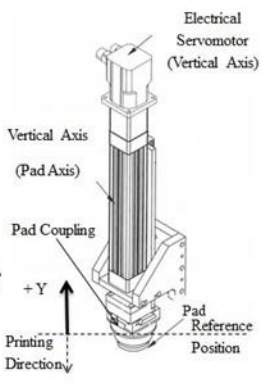

(c)

Figure 6

(a): The pad printing machine unit. The component parts are labeled in the (a) segment. (b): The printing form $(\mathrm{X})$ axis elements [18]. The reference position line and forward direction of movement have been defined here. The printing form table is located at the reference position when the table tip is positioned at the reference position. The printing form receives the ink when moved in the forward direction. (c): The pad (Y) axis elements [18]. The reference position line and printing direction have been defined. The printing direction is in the $-\mathrm{Y}$ direction. The pad and pad axis are located at the reference position when the pad coupling is at the reference position line. 
The main material of the pad is silicon. The pad shape has the two important parameters of pad angle (from side to print area) and pad printing surface [22]. The pad's role is to transfer ink from the printing form to the substrate. The printing form is an etched plate of print motif. Pad printing is divided into two main types: closed and open inking systems. In open inking systems, there is no cover on the ink trough, whereas in closed systems, the ink trough is sealed. Thus, there is more solvent evaporation in open systems than in closed [5, 10]. The inking system discussed in this paper is a closed system. The ink cup (the closed system ink trough) is an ink storage device located on the printing form that delivers the ink to the printing form in each printing cycle [6]. The substrate is an object located on the substrate table on which the printing process is performed. More detailed pictures of the printing form and pad axes from Figure 6 (a) are given in Figure 6 (b) and Figure 6 (c), respectively. The reference (home) position and printing direction of each axis are shown in these figures. The reference position of the printing form table and its forward direction are shown in Figure 6 (b). The printing form table has an electrical servomotor that has been connected to the linear axis by means of a coupling and flange. These accessories allow forward and backward movement of the printing form table. The reference position and $\mathrm{Y}$ direction of the pad axis are shown in Figure 6 (c) (vertical direction). The $\mathrm{Y}$ axis positive direction is upward. In other words, the printing process is performed in the negative direction. The reference position is the connection point of the pad with the pad coupling. The tip of the pad is not selected as the reference point, since pads with different heights may be used at this location.

\section{Pad Printing Working Process}

The pad printing working process is described in Figure 7. The inputs of the flowchart are printing form, ink, pad and substrate (2D or 3D).

Initially, the printing form and pad goes to their reference positions. In the next step, the substrate is fixed on its table. The substrate fixer could be a vacuum table. Briefly, according to this flowchart, the printing form gets the ink from the ink cup and then moves forward. Next, the pad descends and receives the ink from the printing form. The pad then goes up again and the printing form table comes backward. The pad then comes down and is pressed onto the substrate, thus transferring the ink. Finally, the pad ascends, and the printing project is completed. 


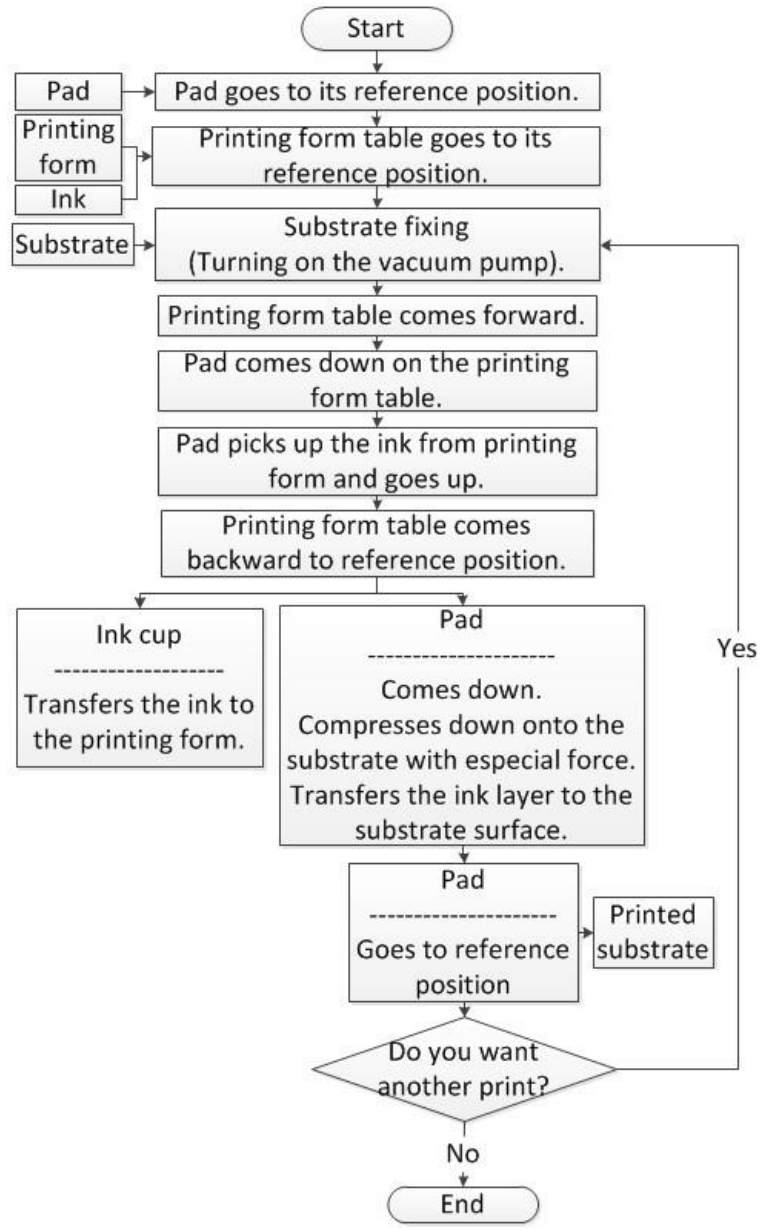

Figure 7

Pad printing working process flowchart. The different steps of the printing process are described here from start to end. The pad, printing form, ink and substrate are input materials and the printed substrate is the output.

\section{Development Process of Pad Printing Machine}

The hardware type, software design and automation level of the system are related to the machine's application.

The hardware for use in scientific fields should be capable of highly accurate control. Then, pursuant to its application, one designs the desired data flow 
between hardware, software and final user. Next, one selects appropriate software according to the hardware and data flow system. Eventually, the programing process is started. In the following, the development process of the machine structure is described. Then, the development of the system's automation level and its data transferring route are discussed. Afterward, the uniquely designed software is presented, with concentration on the user interface (UI).

\subsection{Development of the Machine Structure}

The parts of the machine units we developed are shown in Figure 5. As the most important control unit element, the National Instrument CompactRio (cRIO) 9074 has been used. The cRIO is a real-time, embedded industrial machine controller with additional monitoring capabilities. Its specifications have been described in [20]. With this device, we were able take advantage of features such as a high speed, real-time processor, the ability to add measurement devices as I/O modules and the ability to expand external devices through networking. So, by utilizing these advantages and software features, an on-line controlling and data mining system with data measurement and processing capabilities could be created. Two Kollmorgen AKD servo drives were used as the vertical and horizontal drives of the controlling unit in Figure 5. These drives are capable of multi-axis programmable motion. Moreover, they can measure and control the speed, acceleration, position, torque and current of servomotors. Their response to mechanical load changes is immediate, thus allowing for an appropriate control level. Motor control is possible in three operation modes: torque, velocity and position. In torque mode, the motor current is controlledand the current loop is updated every 0.67 microseconds to achieve an accurate control system. The drives used in the scientific pad printing machine support the EtherCAT protocol for data transferring $[12,19]$. An EtherCAT connection was used as a network protocol in this project [21]. By using EtherCAT, the contact time between the process steps and the CPU load is decreased [3]. It has high-speed performance with an accurate synchronization of less than 1 microsecond between master and slave, a feature important for coordinated motion between the motion axes. Because of its features, EtherCAT is used in machine design, motion control and measurement equipment applications $[3,21]$. To ensure precise, delicate motion control, a quick and synchronized data transferring system is needed. Therefore, in our scientific pad printing machine, the EtherCAT has Kollmorgen drives connected to the cRIO.

An overview of industrial communication systems is shown in Table 2. The maximum bit rate of the EtherCAT data transferring system is $100 \mathrm{Mbit} / \mathrm{s}$, which compares favorably with other methods [9]. The communication relationship of the EtherCAT protocol is master/slave. This means that a device has one-sided control over one or many devices. In the system described in this paper, the CompactRIO hardware, as a real-time, embedded industrial controller, has the role of master for controlling the horizontal and vertical AKD servo drives (slaves). 
Table 2

Different industrial communication systems [9]. The most important parameters of industrial communication systems are the Max. bit rate, Max. number of nodes and the communication relationship. According to the communication specifications of the system hardware, the EtherCAT system is one of the best candidates for the new pad printing machine, since it has a high bit rate (100Mbit/s) and master/slave communication (because in this case two drives are to be controlled by means of a real-time controller).

\begin{tabular}{|l|l|l|l|}
\hline System & $\begin{array}{l}\text { Max. bit } \\
\text { rate }\end{array}$ & Max. Nodes No. & Communication \\
\hline AS-i & $167 \mathrm{kbit} / \mathrm{s}$ & 124 & Master/Slave \\
\hline CAN & $1 \mathrm{Mbit} / \mathrm{s}$ & 127 & Publisher/Subscriber \\
\hline PROFIBUS DP & $12 \mathrm{Mbit} / \mathrm{s}$ & 125 & Master/Slave \\
\hline DeviceNet & $0.5 \mathrm{Mbit} / \mathrm{s}$ & 64 & Master/Slave \\
\hline INTERBUS & $2 \mathrm{Mbit} / \mathrm{s}$ & 512 & Master/Slave \\
\hline SERCOS & $16 \mathrm{Mbit} / \mathrm{s}$ & 255 & Master/Slave \\
\hline PROFINET & $100 \mathrm{Mbit} / \mathrm{s}$ & Unlimited & Master/Slave \\
\hline EtherCAT & $100 \mathrm{Mbit} / \mathrm{s}$ & 65535 & Master/Slave \\
\hline Powerlink & $100 \mathrm{Mbit} / \mathrm{s}$ & 254 & Publisher/Subscriber \\
\hline
\end{tabular}

As shown in Figure 5, a force sensor has been appended to the sensors unit. A single-point load cell with a maximum capacity of $100 \mathrm{~kg}$ and a safe load limit of $150 \mathrm{~kg}$ at a maximum eccentricity of $150 \mathrm{~mm}$ and accuracy class C3 has been used as a force sensor. In addition, a force measurement capability has been added to the printing form table. Ultimately, all of these forces are measured and controlled at a high accuracy level (Min. LC verification interval of $0.1961 \mathrm{~N}$ for max. capacity of $980.665 \mathrm{~N}$ ) as part of the effective parameters of printing quality. In addition to controlling the printing process, the user can store these data for offline data analysis. These capabilities, along with high-speed data transfer over the EtherCAT protocol, validate this machine as a scientific pad printing machine.

\subsection{Development of the Automation Level}

In accordance with the automation pyramid (Figure 2) and the specifications of conventional pad printing machines, most well-known pad printing machines [17, $18,25]$ have normal sensors and actuators and controller devices, such as PLCs. Therefore, based on their features, they are located at level 0 or 1. Although many of them have an input system for entering printing parameters, they do not have process monitoring on their user interface, and thus do not advance to level 2 . The newly designed and automated pad printing machine has reached the second automation level due to its on-line monitoring of the printing process and the parameters on the user interface. Moreover, the ability to alter printing parameters for the next printing sample according to the monitored data and the ability to store, handle and trace data with DIAdem (Version 14, National Instruments) is an 
improvement in the pad printing information management system that could lift the automation level of the new pad printing machine to level 3.

\subsection{Data Flow of the Pad Printing Machine Structure}

The data flow between different units of the pad printing machine is illustrated in Figure 5. In this picture, the arrows point in the direction of the pad printing machine data flow. The user interface (UI) receives demands from the user and sends them to the software Main program of the control unit. After that, at the same unit, these data are transferred to the real-time controller for processing and translating into machine language. Then, the electrical command is sent to the horizontal and vertical drives. Then the data are sent to the actuator unit and, finally, executed by means of printing units in the mechanics unit.

The outputs of this newly designed machine are divided into the two categories of printed objects (printed outputs) and printing specification reports (software outputs). The printed substrate could be a 3-D object (e.g., printed electronic devices on 3-D surfaces). The other output is software based and produces such useful machine reports as printing force or inking force. It should be noted that the data flow route of the machine parts takes place via the EtherCAT protocol with a high-speed data transfer rate (max. bit rate of $100 \mathrm{Mbit} / \mathrm{s})[9,21]$.

\subsection{Software Design}

In this work, the LabVIEW (Version 13, National Instruments) was used to program the embedded FPGAs. The programing procedure of this new machine has been classified into two parts. One part is the Main program and the other part has been designed as a machine user interface (UI). The Main program has various block diagrams. This part has been designed for the control and data processing of different machine units (Control, Actuators, Sensors, Mechanics) according to user demands and the working process flowchart of Figure 7. The LabVIEW programing structures of the Main program were defined pursuant to the flowchart steps of Figure 7 and related working functions were then programmed inside each program structure. This program also processes all measured machine data. In another step, all measured data is sent to another program part, where data management is performed. In every 4 milliseconds, a package of data is sent to the data inventory for research and scientific analysis. 


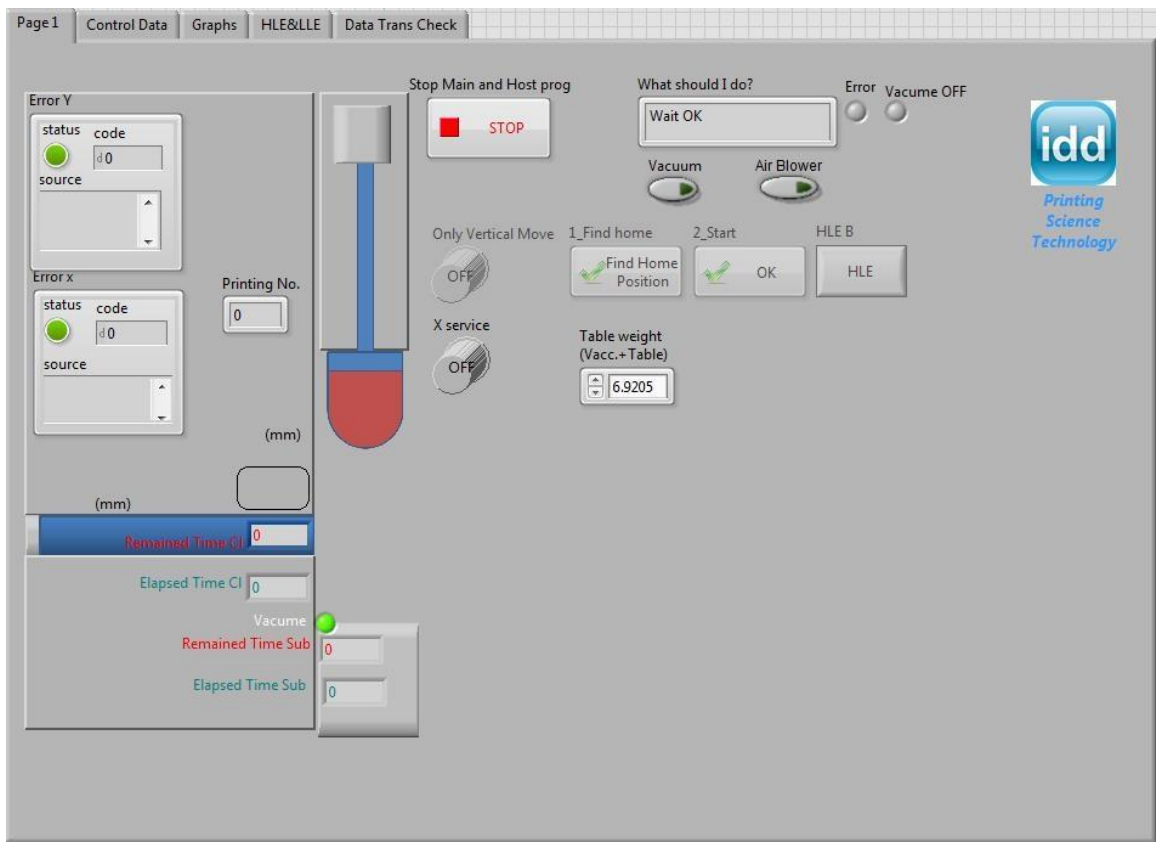

Figure 8

The Operational sub-User Interface (O-UI). The left side of picture shows the on-line printing process graphically. Other parts are the printing operational keys. They are called operational, because of their effect on the operation of the printing process. By pressing the "Find home position", the axes will go to their reference position, and by pressing the "start" button, the printing process will be started.

In front of all these complex processes, there is a supporting program with a graphical part as a mask. We refer to this part of the machine as the user interface (UI). It is divided into different sub-UIs, as shown in Figure 8, Figure 9 and Figure 10. The UI receives the demands of the user and translates them into useful parameters for the control program part. Figure 8 shows the operational sub-UI (O-UI), so named because of the execution functional keys located there, such as "start printing process". In a graphical segment of this sub-UI, the machine working process (pad and printing form movement) is shown on-line as a graphical animation.

In Figure 9, the machine set point sub-UI (SP-UI) is shown. In the SP-UI, the values of the printing parameters are defined. For an easy definition of values, all parameters have been categorized according to the printing steps shown in Figure 3 and the speed limitations have been defined here for input parameters. The ability to save and load parameter data has been added in the SP-UI to make it easy to use the machine and print with the same parameters at different times. The user can define the pad printing working process via automatic force control on the printing form or substrate merely by pushing a button on the SP-UI. The 
contact time on the printing form and the substrate are two other parameters that the user may choose to influence the printing process. All of these options represent advantages of our pad printing machine over conventional machines.

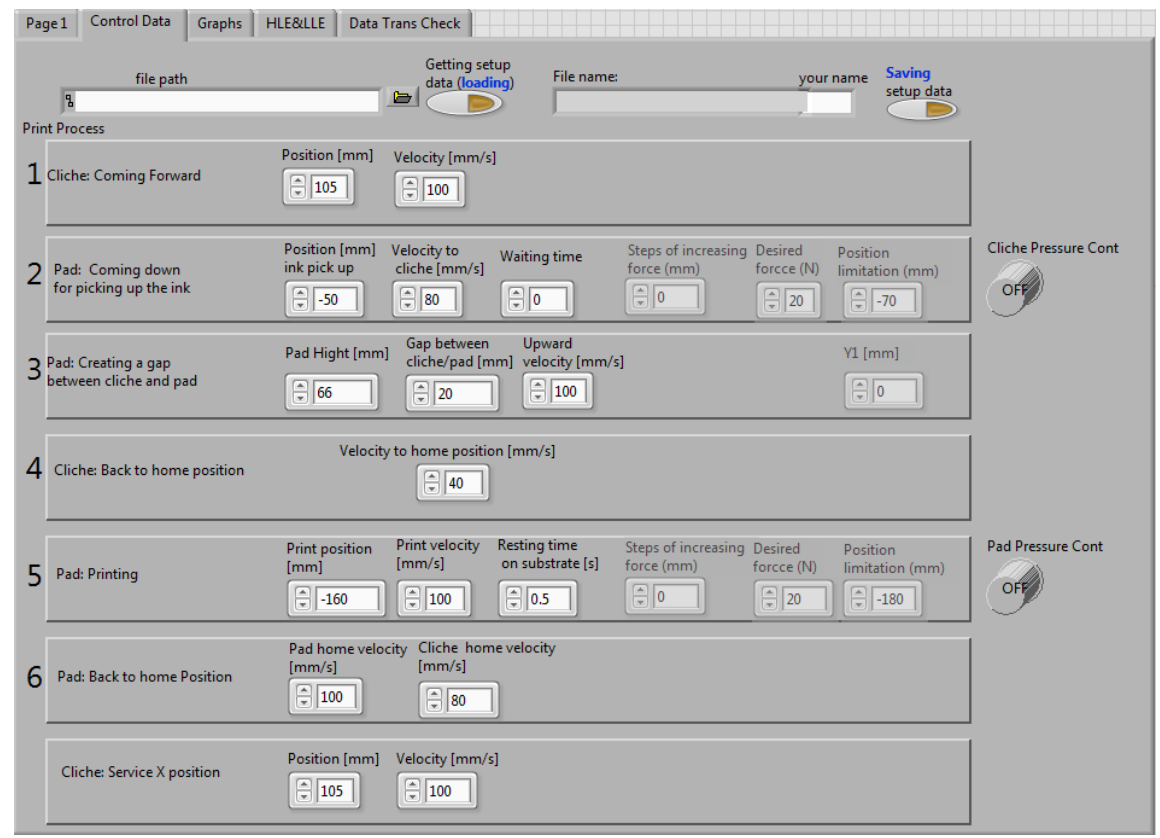

Figure 9

The Set Point sub-User Interface (SP-UI). The different printing parameters are described here by the user. The printing parameters have been categorized according to the printing step involved; the number and description of each step is described at the left side of picture. These classifications make it easy for the user to operate the machine.

Figure 10 shows the on-line Graph Panel sub-User Interface (GP-UI). This panel displays the on-line graphs of the printing force, the printing form force, the position and velocity of the $\mathrm{X}$-axis, and the position and velocity of the $\mathrm{Y}$-axis over time during the printing process. The user can also save the data of the desired graphs in the host computer for further scientific analysis. 


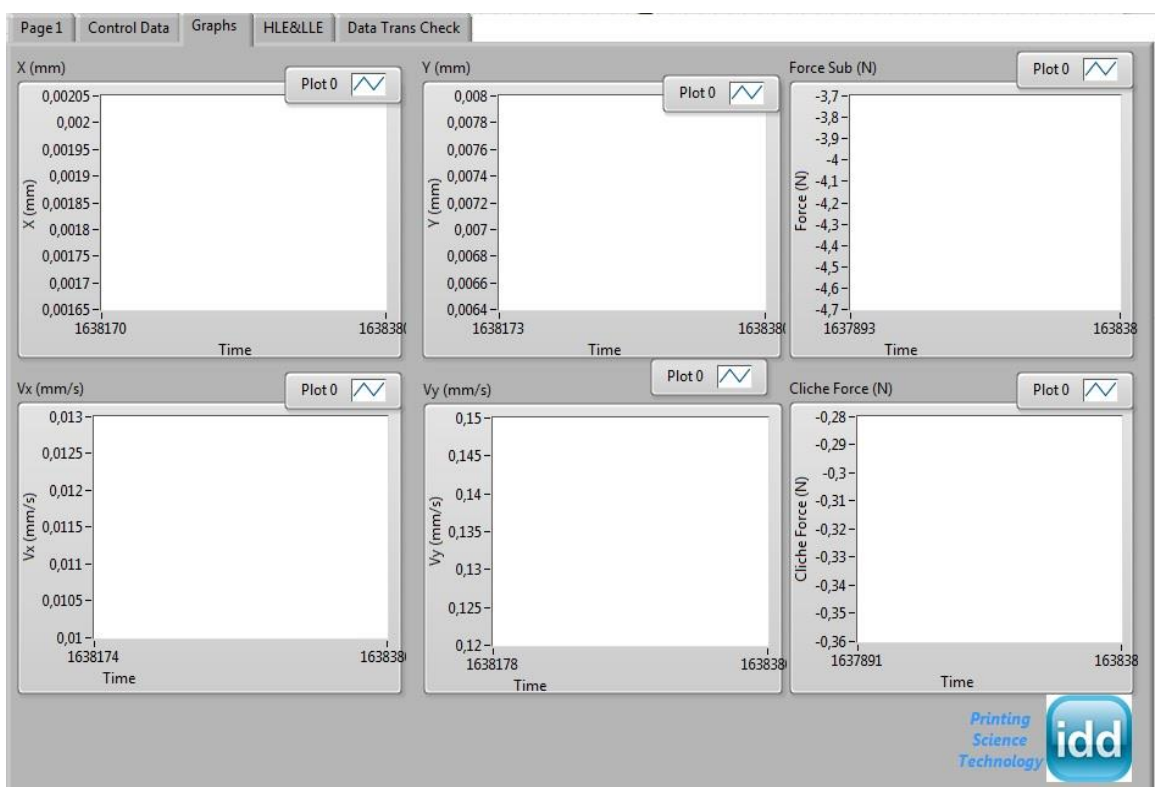

Figure 10

The Graph Panel sub-User Interface (GP-UI). This panel shows the position and velocity of pad and printing form axes, the printing force and ink delivery force (of printing form). All of these 6 diagrams are shown on-line for the duration of the printing process. By means of these graphs, the user can monitor and trace the printing process and make decisions that improve the parameters for subsequent printing iterations.

The main contribution of this work is an improvement of the automation level of pad printing machines. As described in section 5.2, the most well-known pad printing machines $[17,18,25]$ are located at the automation level 1 or 2 , whereas the presented developed machine has reached the automation level 3. According to this novelty, the printing parameters (Figure 9) can be set with sufficient precision. Afterward, the printing process will be executed by the developed control system and other parts (Figure 5) according to the set values, identically. These parameters are adjusted independently of each other. This feature will cause to better controllability of the printing process. As an example, the printing force, speed and pad position can independently be adjusted and controlled. Then, the effect of these parameters on the printing quality and process can be controlled. Whereas, the conventional pad printing machines can not support such aspects.

The pad printing is a complex process and it is important to investigate its process, systematically. Future work should aim to decrease the complexity of the system and to investigate the unknown behaviors of the system during the printing process. The highly automated pad printing machine developed in this work forms an ideal basis for further researches, since it allows for measurement of the printing parameters, and the ability of the database analysis. 


\section{First Results}

Data related to the force, velocity, position and torque of the printing and printing form axes are saved in every 4 milliseconds as software outputs of the machine. These data have a relationship to some of the parameters affecting the printing quality. Thus, depending on user demands, different types of graphs and analyses may be obtained using these data. For example, using an 85 by 75 by $66 \mathrm{~mm}$ pad of hardness 12 Shore A together with a polyethylene terephthalate (PET) substrate of thickness 125 micrometer, a length of $297 \mathrm{~mm}$ and a width of $210 \mathrm{~mm}$, the following results were obtained: Figure 11 shows the movement of the printing form (X) and pad (Y) axes according to the printing steps of Figure 3. The $\mathrm{X}$ curve (green) describes the position and movement of the printing form axis and the $\mathrm{Y}$ curve (red) delineates the pad axis movement versus time. For example, steps 3 and 4 are related to ink pick up. In step 3, the pad goes down to retrieve ink; thereafter, in step 4, the pad goes up again. According to this diagram, you can easily measure the time duration of each printing step.

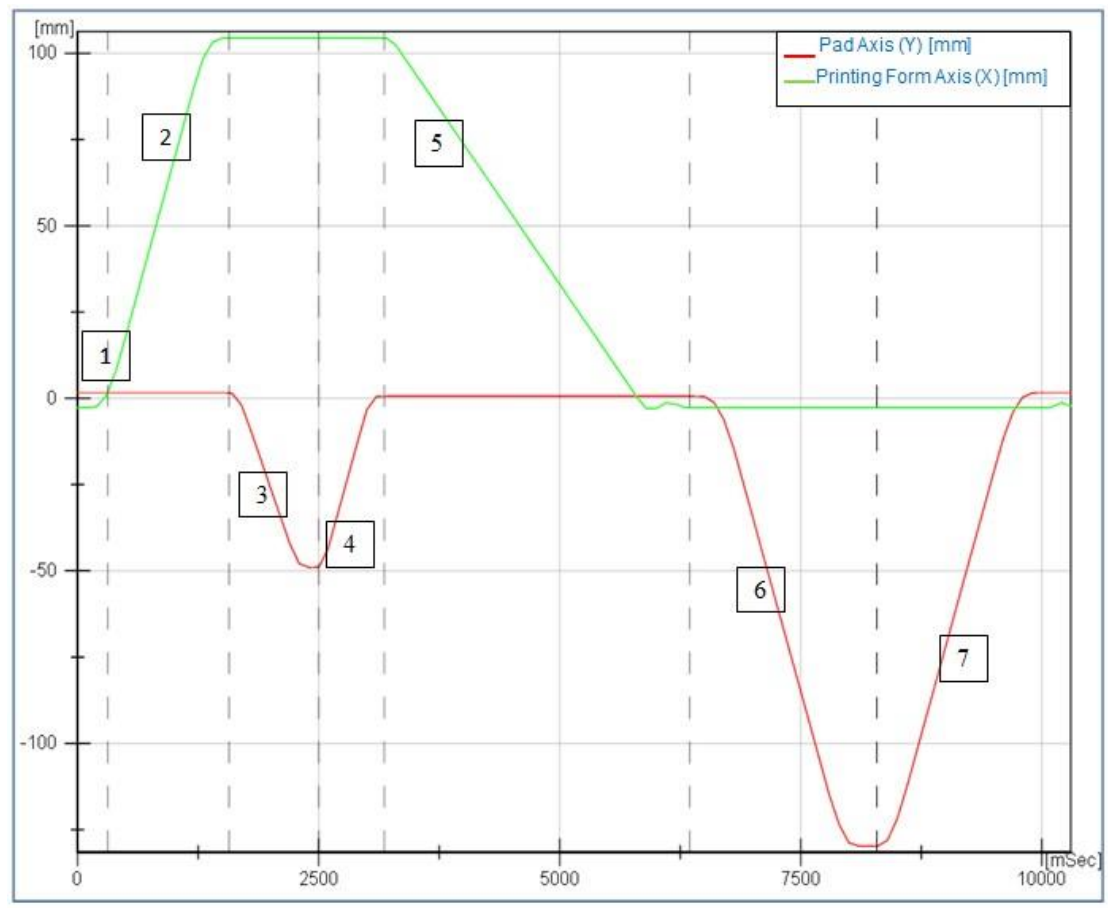

Figure 11

Axes movement diagrams. This graph shows the pad axis movement (red curve) and printing form axis (green curve) over time. The vertical dashed lines show the time duration (millisec) of each printing step, as numbered according to Figure 3 . The highly accurate system measurements permit time units of milliseconds $(\mathrm{mSec})$. The values of pad axis position are negative, since the printing direction is along the $-Y$ axis. 
One type of scientific graph is shown in Figure 12. This graph shows the pad movement behavior versus force for measured data in the pad printing process. The pad movements can be obtained approximately by calculating the force-Y (pad movement) using equation (1) (See dashed line in Figure 12). The F-Y diagram is divided into two parts: Increasing pad force when the pad moves downward on the printing form (step 6 from Figure 3) and decreasing pad force when the pad moves upward (step 7 from Figure 3).

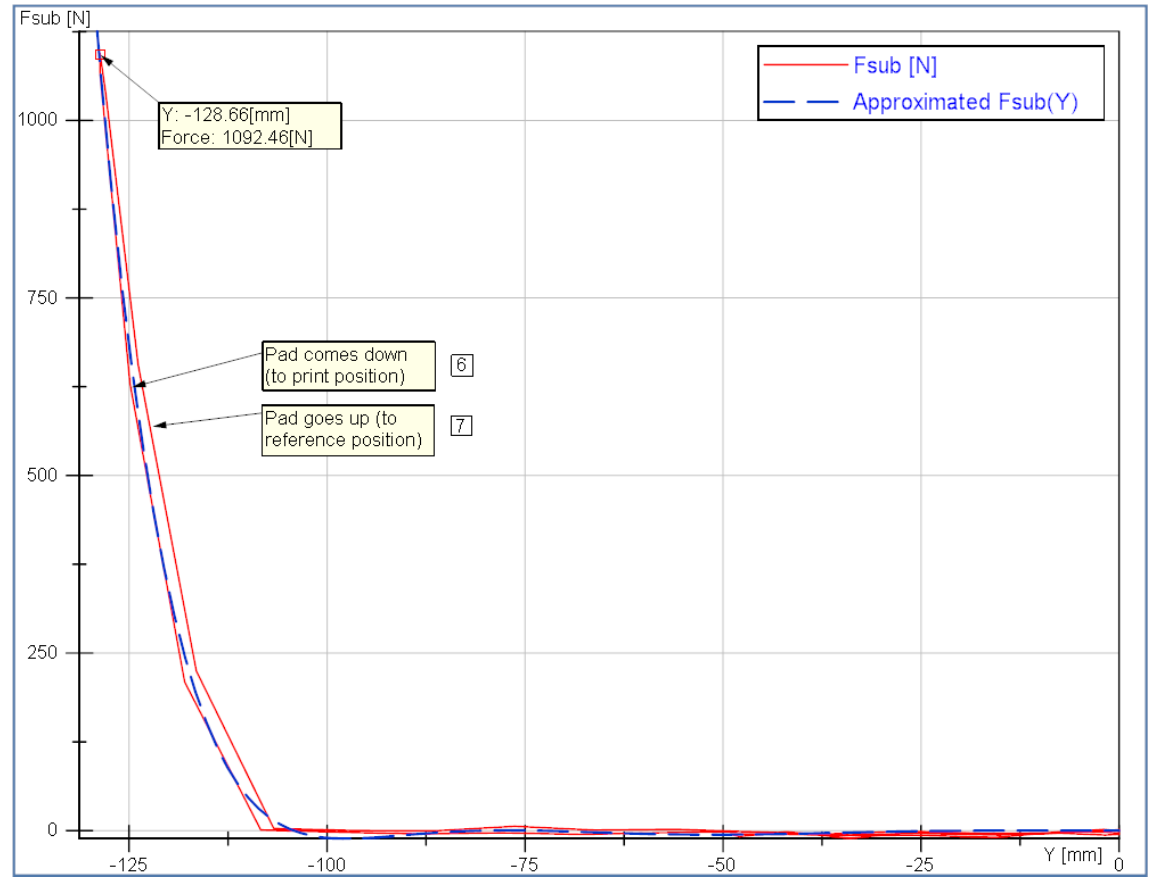

Figure 12

Printing force versus pad movement and its approximate equation diagram. The printing force curve (red) has two parts. The left part is related to pad downward motion for ink transferal and the other is related to pad upward motion after printing on the substrate. They have been signed according to printing steps 6 and 7 (See Figure 3). Because of the printing direction (against Y direction) the pad position values are negative. According to increasing of absolute position value from $|-112| \mathrm{mm}$ till $\mid$ $128.66 \mathrm{~mm}$, the pad is in contact with the substrate and the force is increased. The force-increasing behavior according to pad position in this experiment is an eighth-order equation (equation (1)) whose approximated curve (blue curve) has been derived by means of DIAdem.

Using equation (1), the pad axis movement for printing with a special force (for this type of pad) can be calculated.

$$
\begin{aligned}
& F(Y)=2.927 E 07 * Y^{5}+1.04 E-08 * Y^{6}+1.221 E \\
& -10 * Y^{7}+4.723 E-13 * Y^{8}
\end{aligned}
$$


Thus, our scientific pad printing machine was able to generate scientific graphs and allow conclusions about printing processes and situations, especially for highly intricate objects, such as printed electronic devices.

\section{Summary}

This paper has described the process of development at the automation level and the resulting structure of a pad printing machine, with a focus on scientific applications. The mechatronic system structure has been taken as a machine structure model and the printing unit has been incorporated as part of this system. Some developments have been made regarding the machine structure, such as the use of force sensors, National Instrument CompactRio hardware and Kollmorgen servo drives over EtherCAT data transferring protocol. The goals for these devices are highly accurate data measurements, processing and controlling functions, and high speed data transfer. As a validation of our work, we were able to generate various scientific graphs that reflect the printing process for each printed object (2-D or 3-D). Via these graphs, the user can improve the printing quality for future printing iterations and achieve traceable and repeatable printing. The user can follow the printing graphs on-line via the machine user interface or off-line via DIAdem or related software. All of these developments have led to an increase in the automation level of the pad printing machine. For example, the graph tracing the $\mathrm{X}-\mathrm{Y}$ position movement versus time has been used to determine the duration of different printing steps. The graph of the pad movement versus force for a special pad has been generated and its approximated equation has been derived. This diagram and its related equation are useful for calculating pad axis movement for obtaining a printed object with a special force. The scientific pad printing machine can be used for unique applications, such as printed electronic devices (e. g., OLEDs).

\section{References}

[1] I. Azolibe, E. W. McGookin, J. Houston, and C. Winton, "Serving the Data Needs of Multiple Applications with One Data Source: an Industry Application Case Study," in Symposium on Information Control Problems in Manufacturing (INCOM 2015)/IEEE, Ottowa, Canada, 2015, pp. 1-6

[2] T. G. DECO, (2015), Introduction to Pad Printing - Pad Printing 101, Available: $\quad$ http://www.decotechgroup.com/library/pad-printing/techbulletin-pad-print-101/

[3] ET Group, "Ethercat - the Ethernet Fieldbus," ed. Nuremberg, Germany: EtherCAT Technology Group, 2014, pp. 4-9 
[4] V. Golovanov, J. L. Solis, V. Lantto, and S. Leppävuori, "Different Thickfilm Methods in Printing of One-Electrode Semiconductor Gas Sensors," Sensors and Actuators B: Chemical, Vol. 34, pp. 401-406, Aug. 1996

[5] P. Hahne, Innovative Drucktechnologien: Siebdruck - Tampondruck. Verlag Der Siebdruck, Germany, 2001

[6] P. Hahne, E. Hirth, I. E. Reis, K. Schwichtenberg, W. Richtering, F. M. Horn, et al., "Progress in Thick-Film Pad Printing Technique for Solar Cells," Solar Energy Materials and Solar Cells, Vol. 65, pp. 399-407, Jan. 2001

[7] C. Horváth and Z. Gaál, "Operating Maintenance Model for Modern Printing Machines," Acta Polytechnica Hungarica, Vol. 5, pp. 39-47, 2008

[8] R. Isermann, "Mechatronic Systems-Innovative Products with Embedded Control," Control Engineering Practice, Vol. 16, pp. 14-29, Jan. 2008

[9] E. Kiel and E. Kiel, Drive Solutions: Mechatronics for Production and Logistics. Springer Science \& Business Media, 2008

[10] H. Kipphan, Handbook of Print Media. Springer, Germany, 2000, pp. 442449

[11] A. Knobloch, "Mikroelektronikschaltungen aus gedruckten Polymeren," Technische Physik, Friedrich-Alexander-Uni., Germany, ErlangenNurnberg, 2003

[12] C. Kollmorgen, "AKD Servo Drive Datasheet," ed. USA: Kollmorgen, 2010

[13] F. C. Krebs, "Pad Printing as a Film Forming Technique for Polymer Solar Cells," Solar Energy Materials and Solar Cells, Vol. 93, pp. 484-490, Apr. 2009

[14] M. Lethiecq, R. Lou-Moeller, J. A. Ketterling, F. Levassort, L. P. TranHuu-Hue, E. Filoux, et al., "Non-Planar Pad-printed Thick-Film Focused High-Frequency Ultrasonic Transducers for Imaging and HIFU Applications," in International Symposium on Piezoresponse Force Microscopy and Nanoscale Phenomena in Polar Materials, 2011, pp. 1-4

[15] F. Levassort, E. Filoux, M. Lethiecq, R. Lou-Moler, E. Ringgaard, and A. Nowicki, "P3Q-3 Curved Piezoelectric Thick Films for High Resolution Medical Imaging," in Ultrasonics Symposium, IEEE, 2006, pp. 2361-2364

[16] S. Merilampi, T. Björninen, L. Ukkonen, P. Ruuskanen, and L. Sydänheimo, "Characterization of UHF RFID Tags Fabricated Directly on Convex Surfaces by Pad Printing," The International Journal of Advanced Manufacturing Technology, Vol. 53, pp. 577-591, Mar. 2011

[17] C. Micro Print, "Pad Printing Catalog," 3 ed. Switzerland: Micro Print LC $\mathrm{GmbH}, 2014$, p. 72 
[18] T. Morlock, "Tampondruck GFG 100," ed. Dornstetten, Germany: ITW MORLOCK GmbH, 2012

[19] T. National Instruments (2012, Aug.), Applications for EtherCAT RIO, White Papers [Technical Document], Available: http://www.ni.com/whitepaper/14083/en/

[20] T. National Instruments (2014, Oct.), CompactRIO Integrated Systems with Real-Time Controller and Reconfigurable Chassis NI cRIO-907x, [Datasheet], pp. 1-8, Available: http://sine.ni.com/ds/app/doc/p/id/ds204/lang/en

[21] T. National Instruments (2012, Aug.), NI EtherCAT RIO: Deterministic Expansion for LabVIEW RIO Systems, White Papers [Technical Document], Available: http://www.ni.com/white-paper/7299/en/

[22] T. Proell (2014, Oct.), Pad Printing Theory and Practice, Pad Printing Inks [Thechnical data], pp. 1-38, Available: http://www.proell.de

[23] T. Robles, R. Alcarria, D. Martın, M. Navarro, R. Calero, S. Iglesias, et al., "An IoT-based Reference Architecture for Smart Water Management Processes," Journal of Wireless Mobile Networks, Ubiquitous Computing, and Dependable Applications (JoWUA), Vol. 6, pp. 4-23, 2015

[24] D. Sharp, "Printed Composite Electrodes for In-Situ Wound pH Monitoring," Biosensors and Bioelectronics, Vol. 50, pp. 399-405, Dec. 2013

[25] C. TAMPOPRINT, "Pad Printing Machines," ed. Korntal-Münchingen, Germany: TAMPOPRINT AG, 2014, pp. 4-11

[26] D. P. Xenos, M. Cicciotti, G. M. Kopanos, A. E. F. Bouaswaig, O. Kahrs, R. Martinez-Botas, et al., "Optimization of a Network of Compressors in Parallel: Real Time Optimization (RTO) of Compressors in Chemical Plants - An Industrial Case Study," Applied Energy, Vol. 144, pp. 51-63, Apr. 2015

[27] X. Ye and Q. Zengchao, "Antenna 3D Pad Printing Solution Evaluation," in IEEE International Symposium on Antennas and Propagation (APSURSI), 2011, pp. 2773-2776 